\title{
Bacillus thuringiensis Cry1C resistance development and its processing pattern in Egyptian cotton leaf worm: Spodoptera littoralis (Boisd.) (Lepidoptera:Noctuidae)
}

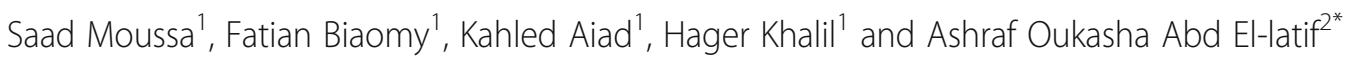

\begin{abstract}
Biopesticides based on the entomopathogenic bacterium, Bacillus thuringiensis toxins, have shown high ability to control several pests belonging to order Lepidoptera. Egyptian cotton leaf worm, Spodoptera littoralis (Boisd.) (Lepidoptera:Noctuidae), is a major pest that attacks various crops in Egypt, and Cry1C toxin-based formulations are heavily used to its control. A laboratory investigation was conducted to study the resistance development in $S$. littoralis against $\mathrm{Cry} 1 \mathrm{C}$ toxin. Thus, a field strain of $\mathrm{S}$. littoralis was selected and maintained under laboratory conditions for 12 generations. The selection pressure resulted in 32.12-fold of resistance ratio after 12 generations. The hydrolysis of Cry $1 \mathrm{C}$ toxin by the midgut extracts of the susceptible line, and the resistant line was compared. Results revealed that $\mathrm{Cry} 1 \mathrm{C}$ toxin was hydrolyzed more rapidly in the resistant line than the susceptible one. The Cry $1 \mathrm{C}$ toxin was processed till 1 hour after incubation in the susceptible line; but in case of resistant line, the Cry $1 \mathrm{C}$ toxin was degraded in 1 hour after incubation.
\end{abstract}

Keywords: Bacillus thuringiensis toxins, Cry1C toxin, Resistance development, Spodoptera littoralis

\section{Background}

The Egyptian cotton leaf worm, Spodoptera littoralis (Boisd.) (Lepidoptera:Noctuidae), is an important polyphagous and destructive pest that attacks various crops in Egypt and many other countries all over the world. Continuous and repetitive use of pesticides caused environmental contamination, and the pests raised insecticidal resistance (Koul, 1982). Therefore, the use of biological control for management of the insect pests (as a safe alternative control method) became an urgent requirement to preserve the environment and natural enemies (Bale et al., 2007).

The biopesticides based on insecticidal crystal protein of $B$. thuringiensis (Bt) toxin had been widely used in

\footnotetext{
*Correspondence: ashrafoukasha@agr.sohag.edu.eg

2Department of Plant Protection, Faculty of Agriculture, Sohag University, Sohag, Egypt

Full list of author information is available at the end of the article
}

insect control. In the midgut of sensitive pests, the $B t$ protoxin is activated by the gut proteases into active toxin, which binds to specific receptors like cadherin and aminopeptidase- $\mathrm{N}$ or alkaline phosphates in the peritrophic membrane, forming pores in the midgut epithelial cells (Fortier et al. 2007, Abdullah et al. 2009, and Talaei-Hassanloui et al. 2014).

Currently, $B t$ formulations that are promoted for lepidopteran control contain the Bt subsp. aizawai. This subspecies produces various Cry1 toxins including Cry1C, which has been shown to be highly toxic to S. littoralis (Chaufaux et al. 1997).

The first report of resistance to $B t$ toxins was by McGaughey (1985) in Poldia interpunctata (Hubner), and later, many other cases were reported either in field or after laboratory selection, e.g., S. littoralis (Müller-Cohn et al. 1996), Helicoverpa zea (Luttrell et al. 2004 and 
Tabashnik et al. 2008), Spodoptera frugiperda (Kruger et al. 2009), and Busseola fusca (Strydom et al. 2019).

Recently, dependence on $B t$-pesticides to control cotton leaf worm in Egypt has been increased, and due to the economic importance of the cotton crop, these compounds are applied repeatedly for several times per season in the cotton fields. However, very little information is available on the status of $B t$ resistance in $S$. littoralis in Egypt.

This research therefore reports studies on the resistance development to $B t$ Cry1C toxin in the Egyptian cotton leaf worm and its processing pattern.

\section{Materials and methods Insect culture}

Larvae of the cotton leaf worm, S. littoralis, originally collected from cotton fields located in Kafer Elsheikh Governorate, Egypt, were reared on the artificial diet described by Kranthi (2005) at $27 \pm 1{ }^{\circ} \mathrm{C}, 70 \% \mathrm{RH}$, and a photoperiod of 14:10 (L:D) h. After pupation, the pupae were collected and kept in glass jars until adult emergence. The adults were allowed to feed on $10 \%$ sugar solution and lay eggs in the same jars. The eggs were collected on tissue paper and kept in small jars along with a wetted cotton piece as a source of moist for hatching.

\section{Preparation of B. thuringiensis Cry1C toxin}

Cry1C toxin was cultured and purified as described by Abdullah et al. (2009) and modified by Moussa (2009). The bacterial cells were inoculated in a $5-\mathrm{ml}$ culture tube for overnight. The overnight culture was then subcultured in a 1-L flask to grow further for $3-5$ days in T3 medium (3.0 g Trypton, $2.0 \mathrm{~g}$ Tryptose, $1.5 \mathrm{~g}$ yeast extract, $\left.0.0005 \mathrm{~g} \mathrm{MnCl}_{2}, 8.9 \mathrm{~g} \mathrm{NaH}_{2} \mathrm{PO}_{4}\right)$. The growth was harvested at $5200 \mathrm{rpm}$ for $10 \mathrm{~min}$ at $4{ }^{\circ} \mathrm{C}$. The pellets were collected and washed in (50 mM EDTA) buffer for 4-6 times/each with $10,000 \mathrm{rpm}$ for $10 \mathrm{~min}$ at $4{ }^{\circ} \mathrm{C}$. The obtained pellet was re-suspended in $5 \mathrm{ml}$ of $(50 \mathrm{mM}$ Tris, $\mathrm{HCl}, 5 \mathrm{mM}$ EDTA, pH 7.0) buffer. These inclusion bodies were examined by $10 \%$ SDS-PAGE gel electrophoresis. The protein concentration was determined using the Bradford method according to Bradford (1976). The inclusion bodies were then aliquoted in 1.5 $\mathrm{ml}$ Eppendroff tubes and stored at $-20^{\circ} \mathrm{C}$.

\section{Bioassay of Cry1C toxin}

Bioassay Cry1C toxin was conducted using diet incorporation method. Five different concentrations of Cry1C toxin in water were prepared, and 4 replicates for each concentration were represented. Moreover, the control replicates were treated by $\mathrm{dH}_{2} \mathrm{O}$ instead of Cry1C toxin. Twenty newly hatched neonates were placed onto the surface of the diet in each replicate, using a thin brush and then kept under laboratory conditions. The larval mortality was recorded 7 days after treatment, and the median lethal concentration $\mathrm{LC}_{50}$ was calculated according to Finney (1971).

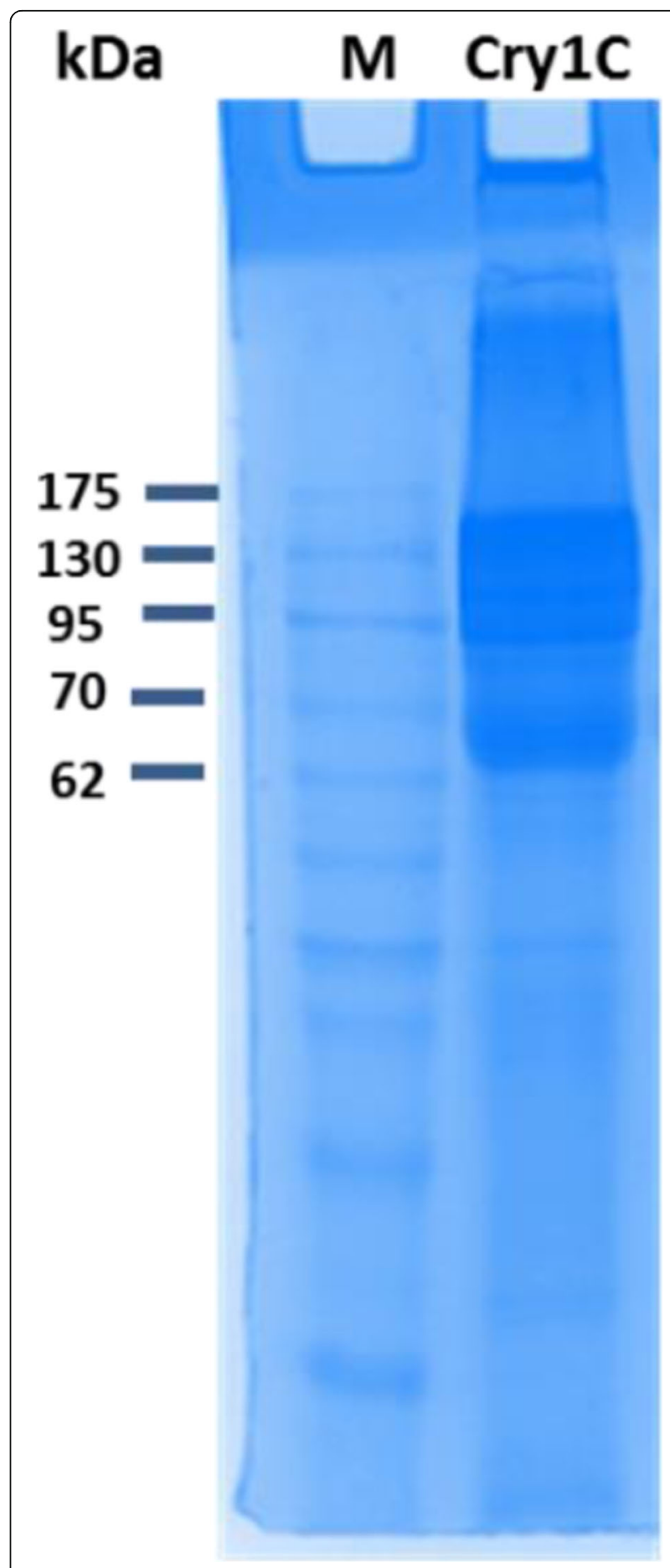

Fig. 1 SDS-PAGE of partially purified Cry $1 C$ toxin. M, Chromatin prestained marker; Cry $1 \mathrm{C}, \mathrm{BtCry} 1 \mathrm{C}$ toxin 


\section{Selection pressure}

Selection of $S$. littoralis neonates for resistance was initiated by transferring of 500 neonates onto the surface of artificial diet incorporating Cry1C toxin for 4 subsequent days with care always taken to obtain about $75 \%$ mortality or higher. The survived larvae were then transferred to feed on toxin-free diet until pupation. The emerged adults were allowed to feed on $10 \%$ sugar solution. The laid eggs were collected and kept in plastic cups along with wetted cotton piece until hatching. The above selection procedure was repeated on the newly hatched neonates of the second generation, and this regular work was performed at every generation until 12 generations. The bioassay was conducted at F1, F3, F6, F9, and F12 in order to calculate the $\mathrm{LC}_{50}$. Resistance ratios were calculated by dividing the $\mathrm{LC}_{50}$ of selected generation by the $\mathrm{LC}_{50}$ of $\mathrm{F} 1$.

\section{Preparation of gut extract}

Gut extract was performed referring to the method described by Moussa (2009). Ten 4th instar larvae were dissected on ice, and their guts were pooled in $300 \mu \mathrm{l}$ $\mathrm{dH}_{2} \mathrm{O}$ in microcentrifuge tubes. An amount of 1.5 phenyl methane sulfonyl fluriode (PMSF) was added to inhibit proteinase enzymes. The guts were grinded gently then centrifuged at $14,000 \mathrm{rpm}$ for $15 \mathrm{~min}$ at $4{ }^{\circ} \mathrm{C}$. The supernatant was carefully transferred into sterilized Eppendorf tubes and kept at $-20^{\circ} \mathrm{C}$ for further use.

\section{Digestion and processing of Cry $1 \mathrm{C}$ toxin}

In order to compare the processing of Cry1C toxin in the midgut of susceptible (F1) and resistant line (F12) of the cotton leaf worm, an amount of $50 \mu \mathrm{l}$ gut extract sample was mixed with $10 \mu \mathrm{g}$ of Cry1C toxin in microcentrifuge tube, and the volume was completed to $25 \mu \mathrm{l}$, using universal buffer (11.5 mM boric acid, $7.8 \mathrm{nM}$ citric acid, $18.7 \mathrm{mM} \mathrm{Na} 2 \mathrm{HPO} 4$, and $68.9 \mathrm{mM} \mathrm{NaOH}, \mathrm{PH} 9.75$ ) (Frugoni 1957). Samples were incubated at room temperature at different time intervals, viz., 5, 15, 30 $\mathrm{min}$, and $1 \mathrm{~h}$ with Cry1C toxin. Toxin processing was terminated by heating the sample at $100{ }^{\circ} \mathrm{C}$ for $5 \mathrm{~min}$. The samples were cooled down at room temperature, and sample buffer was added. The samples were again boiled for $5 \mathrm{~min}$ for protein digestion (Moussa 2009). Finally, the samples were analyzed using SDS-PAGE (4\% stalking gel and $10 \%$ separating gel).

\section{Results and discussion}

Cry1C toxin-based insecticide is being repetitively used to control S. littoralis in Egypt. In 1996, a strain of S. littoralis was selected with Cry1C toxin that developed 500-fold resistance (Muller-Cohn et al. 1996). Another case of Cry1C toxin resistance was reported by Chaufaux et al. (1997) as after selection that the 12th generation of S. littoralis showed more than 500-folds of resistance than the control. In the present experiment, neonates of $S$. littoralis were selected against Cry1C toxin. Cry1Ctoxin was purified from $B t$ culture, and the concentration of Cry1C toxin stock solution was $0.5 \mu \mathrm{g} / \mu \mathrm{l}$. The stock solution of Cry1C toxin was checked on SDSPAGE gel and its band appeared at $65 \mathrm{kDa}$ molecular weight (Fig. 1).

\section{Development of resistance}

Before selection, the larvae of S. littoralis (F1) were sensitive to Cry1C toxin with $\mathrm{LC}_{50}$ of $0.17 \mu \mathrm{g} / \mathrm{g}$ diet (Table 1). $\mathrm{LC}_{50}$ of Cry1C toxin increased to $2.40 \mu \mathrm{g} / \mathrm{g}$ diet in F3 than F1 with resistance ratio of 14.12 folds. $\mu \mathrm{g} / \mathrm{g}$ diet. The resistance ratio increased from generation to another until it reached 32.12 folds in F12. The present data cleared that $S$. littoralis had the ability to develop the resistance to $B t$ toxins, while exposed to diet mixed with the toxin for subsequent generations, as other lepidopteran pests (Tabashnik et al., 1997 and Moussa and Gujar, 2005).

The earlier studies proved that laboratory strain of the cotton leaf worm had evolved moderate resistance in 8 subsequent generations of selection pressure against inclusion bodies of CrylC toxin. The resistance ratio reached 5.8 and 3.4-folds for the Egyptian local $B t$ isolates of DI29 and entomocidus, respectively. Additionally, when the cotton leaf worm was selected against commercialized $B t$ formulations of Agerin and Diple $2^{\mathrm{x}}$, the $\mathrm{LC}_{50}$ increased to 20.5 and 16.3-folds, respectively (Mohammed 1997). The spore/crystal mixture used in the previous study might contain associated particles that may delay resistance

Table 1 Resistance development in Spodoptera littoralis laboratory selected line against Cry $1 \mathrm{C}$ toxin

\begin{tabular}{lllll}
\hline Generation & $L C 50(\mu \mathrm{g} / \mathrm{g}$ diet $)$ & $95 \%$ confidence limit & Slope \pm Se & Resistance ratio (RR) \\
\hline F1 & 0.17 & $0.11-0.24$ & $1.39 \pm 0.16$ & 14.12 \\
F3 & 2.40 & $2.06-3.01$ & $2.87 \pm 0.59$ & 22.00 \\
F6 & 3.74 & $2.84-5.35$ & $1.80 \pm 0.37$ & 31.71 \\
F9 & 5.39 & $4.33-7.61$ & $2.33 \pm 0.47$ & 32.12 \\
F12 & 5.46 & $4.75-6.60$ & $2.79 \pm 0.47$ & \\
\hline
\end{tabular}

$R R$ resistance ratio $\left(\mathrm{LC}_{50}\right.$ of resistance/ $L \mathrm{C}_{50}$ of $\mathrm{F} 1$ strain) 


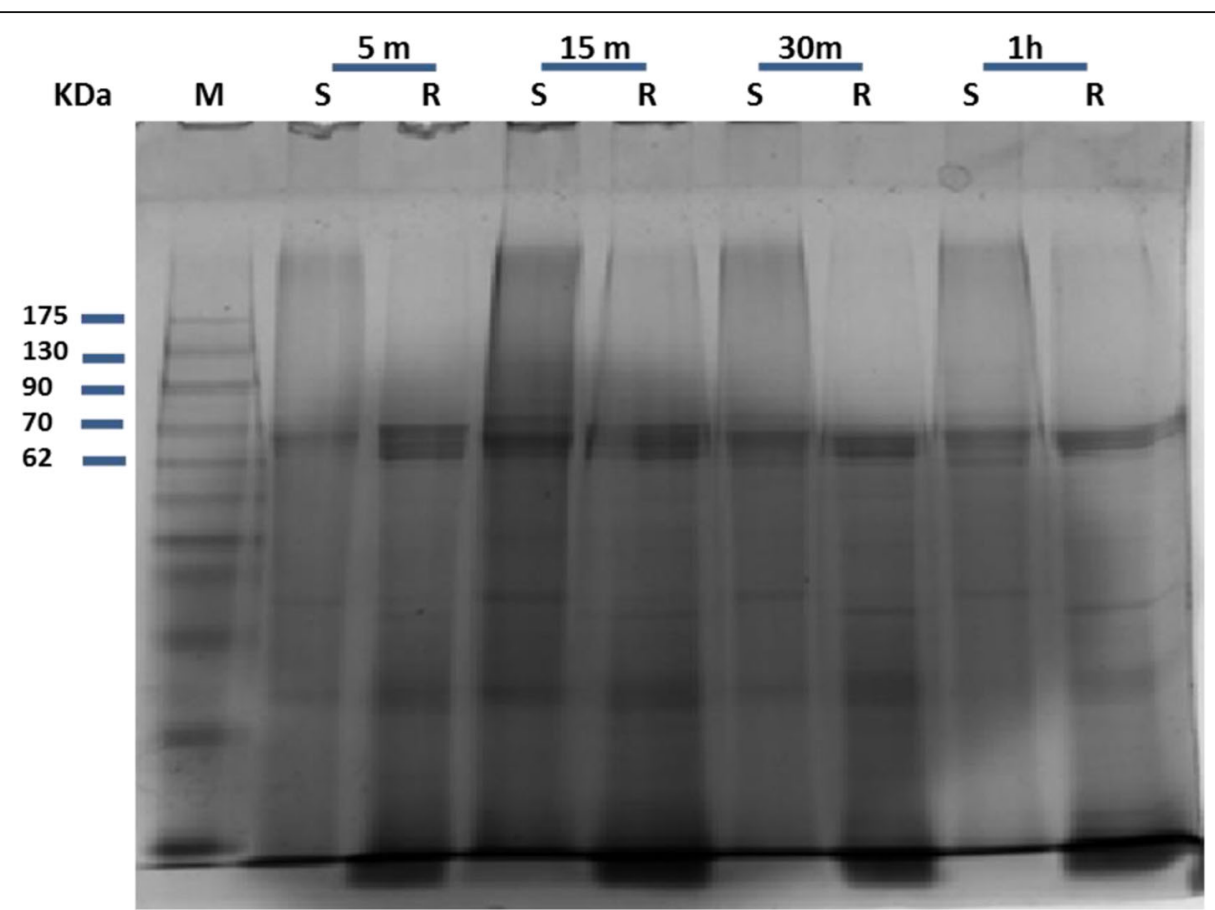

Fig. 2 Hydrolysis of $\mathrm{Cry} 1 \mathrm{C}$ toxin by the gut extract of Spodoptera littoralis susceptible and resistant lines incubated at different time intervals, viz., 5, 15, 30, and 60 min. M, page ruler marker; S, susceptible lane; R, resistant lane

development in cotton leaf worm strain compared to purified toxins in the present investigation.

\section{Processing of Cry1C by S. littoralis midgut extract}

In the present study, the hydrolysis of Cry1C toxin by the midgut extracts in the susceptible line of $S$. littoralis (F1) and the resistant line (F12) was studied to determine if there were differences in protoxin activation in both lines. The Cry1C partially purified toxin was incubated with their gut extracts at different time intervals, viz., 5, 15, $30 \mathrm{~min}$, and $1 \mathrm{~h}$. Then, the samples were separated on SDS-PAGE. Results revealed that at $5 \mathrm{~min}$ after incubation, one fragment of $65 \mathrm{KDa}$ appeared in susceptible line, while 3 fragments were observed between 62 and $70 \mathrm{KDa}$ in resistant line (Fig. 2).

After 15 min of incubation, 3 fragments between 65 and $70 \mathrm{kDa}$ appeared in the susceptible line. On the other hand, after $30 \mathrm{~min}$ of incubation with gut extract of resistant line, one more lowering band at $65 \mathrm{kDa}$ appeared but did not appear in the susceptible line. When Cry1C was incubated by gut extract for $1 \mathrm{~h}$, the upper band at $70 \mathrm{kDa}$ position in resistant line was totally disappeared, and the lowest band became thicker; however, the same band in susceptible line was not totally degraded despite the lowest band was increased. The above observation revealed that the degradation of the Cry1C fragment in resistant line was faster than in the susceptible line. The processing of Cry1C toxin with susceptible and resistant lines varied at different time intervals. In susceptible line, the Cry $1 \mathrm{C}$ toxin was processed till $1 \mathrm{~h}$ after incubation. But in case of resistant line, the Cry1C toxin was degraded in $1 \mathrm{~h}$ after incubation. This data is in agreement with that reported by Moussa (2009) who mentioned that Cry1Ac toxin was digested and processed in Helicoverpa armigera $(\mathrm{H}$.) within an hour after treatment.

\section{Conclusions}

The present study proved that the Egyptian cotton leaf worm, S. littoralis, has the ability to build up the resistance gradually, while exposure to $B t$ toxin for subsequent generations. Additionally, the $B t$ toxin was hydrolyzed more rapidly in the resistant line than in the susceptible one.

\section{Abbreviation \\ Bt: Bacillus thuringiensis}

\section{Acknowledgements}

The authors gratefully thanked the Science and Technology Development for Fund (STDF) for funding this work through the project number 375.

\section{Authors' contributions}

SM planned the outline of the research work. AOA prepared the manuscript, while all authors equally did the bioassay experiments. The authors have read and approved the final manuscript.

\section{Funding}

The research work is funded by the Science and Technology Development for Fund (STDF) through the project number 375. 


\section{Availability of data and materials}

The datasets used and/or analyzed during the current study are available from the corresponding author on reasonable request.

\section{Ethics approval and consent to participate}

Not applicable

\section{Consent for publication}

Not applicable

\section{Competing interests}

The authors declare that they have no competing interests.

\section{Author details}

${ }^{1}$ Insect Biotechnology and Molecular Biology Unit, Plant Protection Research Institute (PPRI), Agricultural Research Center, 7 Nadi El-Seid St., Dokki, Giza 62156, Egypt. ²Department of Plant Protection, Faculty of Agriculture, Sohag University, Sohag, Egypt.

Received: 4 January 2020 Accepted: 16 March 2020

Published online: 01 April 2020

\section{References}

Abdullah, M. A. F.; Moussa, S.; Taylor, M. D. and Adang, M. J. (2009) Manduca sexta (Lepidoptera: Sphingidae) cadherin fragments function as synergists for Cry $1 \mathrm{~A}$ and Cry1C Bacillus thuringiensis toxins against noctuid moths Helicoverpa zea, Agrotis ipsilon and Spodoptera exigua. Pest Manag Sci., 65: (10) 1097-1103.

Bale JS, van Lenteren JC, Bigler F (2007) Biological control and sustainable food production. Philosophical transactions of the Royal Society of London. Series B, Biological sciences 363(1492):761-776

Bradford M (1976) A rapid and sensitive method for the quantitative of microgram quantities utilizing the principle of protein-dye binding. Anal Biochem. 72:248-254

Chaufaux, J., Muller-Cohn, J., Buisson, C., Sanchix, V., Lereclus, D. and Pasteur, N., (1997) Inheritance of resistance to the Bacillus thuringiensis Cry1 C toxin in Spodoptera littoralis (Lepidoptera: Noctuidae), J Econom Entomol. 90, 873878

Finney, D.J. (1971) Probit Analysis, third ed., Cambridge University Press, Cambridge, UK

Fortier M, Vachon V, Frutos R, Schwartz JL, Laprade R (2007) Effect of insect larval midgut proteases on the activity of Bacillus thuringiensis Cry toxins. Appl. Environ. Microbiol. 73:6208-6213. https://doi.org/10.1128/AEM.01188-07

Frugoni, J. A. C. (1957) Tampone universale di Britton e Ronbinson a for Za ionica constante. (Gazz. Chim. Ital.) 87: 403-407.Koul O., (1982) Insect feeding deterrents in plants. Indian Rev. Life Sci. 2:97-125.

Kranthi KR (2005) Insecticide resistance -monitoring, mechanisms and management manual'. Published by CICR, Nagpur, India and ICAC, Washington

Kruger MJ, van Rensburg JBJ, Van den Berg J (2009) Perspective on the development of stem borer resistance to Bt maize and refuge compliance at the Vaalharts irrigation scheme in South Africa. Crop Protection 28:684-689

Luttrell, R.G., Ali, I., Allen, K.C., Young, S. Y., Szalanski, A., Williams, K. and Lorenz G., (2004) Resistance to Bt in Arkansas populations of cotton bollworm, pp. 1373-1383. In D. A. Richter (ed.), Proceedings, Belt wide Cotton Conferences, 5-9 January 2004, pp. 5-9. National Cotton Council of America, Memphis.

Mc-Gaughey HW (1985) Insect resistance to the biological insecticide Bacillus thuringiensis. Science 229:193-195

Mohammed AM (1997) Development and characterization of resistance to some biocides in cotton leaf worm Spodoptera littoralis. Ain Shams University, Faculty of Science, M.Sc. thesis, 102 pages

Moussa MS (2009) Processing analysis of Bacillus thuringiensis Cry1Ac in susceptible and resistant selected strains of Helicoverpa armigera. Bull. ent. Soc. Egypt 35:91-101

Moussa, M. S. and Gujar, G. T. (2005) Inheritance of Cry1AC resistance in the transgenic Bt cotton selected strain of the cotton bollworm, Helicoverpa armigera (Hubner), Egypt. J. Agric. Res., 83 (3), 1061-1078.

Müller-Cohn, J., Chaufaux, J., Buisson, C. and Gilois, N. (1996) Spodoptera littoralis (Lepidoptera: Noctuidae) resistance to CrylC and cross-resistance to other Bacillus thuringiensis crystal toxins. J Econ Entomol, 89(4):791-797.
Strydom E, Erasmus A, du Plessis H, Van den Berg J (2019) Resistance status of Busseola fusca (Lepidoptera: Noctuidae) populations to single- and stackedgene Bt maize in South Africa. J Econ Entomol 112(1):305-315. https://doi. org/10.1093/jee/toy306

Tabashnik BE, Gassmann AJ, Crowder DW, Carrière Y (2008) Insect resistance to Bt crops: evidence versus theory. Natl. Biotechnol. 26:199-202

Tabashnik BE, Liu YB, Finson N, Masson L, Heckel DG (1997) One gene in diamondback moth confers resistance to four Bacillus thuringiensis toxins. Proc. Natl. Acad. Sci. USA. 94:1640-1644

Talaei-Hassanloui, R., Bakhshaei, R., Hosseininaveh, V., and Khorramnezhad, A. (2014) Effect of midgut proteolytic activity on susceptibility of lepidopteran larvae to Bacillus thuringiensis subsp. kurstaki. Front Physiol, 4, 406.

\section{Publisher's Note}

Springer Nature remains neutral with regard to jurisdictional claims in published maps and institutional affiliations.

\section{Submit your manuscript to a SpringerOpen ${ }^{\circ}$ journal and benefit from:}

- Convenient online submission

- Rigorous peer review

- Open access: articles freely available online

High visibility within the field

- Retaining the copyright to your article

Submit your next manuscript at $\boldsymbol{\sim}$ springeropen.com 